\title{
BANK SAMPAH DAUR ULANG DAPAT UANG
}

\author{
U.E. Suryadi ${ }^{1}$, U.S.Y.V.Indrawati ${ }^{2}$, A. Aspan ${ }^{3}$
}

\begin{abstract}
ABSTRAK
Pengabdian Masyarakat yang dilaksanakan di Bank Sampah "Daur Ulang Dapat Uang“ bertujuan untuk memberikan teknologi bagaimana menerapkan sistem keuangan dan sistem pembukuan Bank Sampah yang benar dan akan ditransfer teknologi pembuatan kompos dari sampah organic dan teknologi pembuatan tas, dompet cantik dari sisa-sisa bungkus plastik atau sampah an organic kepada Kelompok Usaha Remaja Mandiri dan Kelompok Usaha Maju Bersama. Kegiatan pengabdian ini akan dilaksanakan di Kelurahan Sungai Bangkong, Kecamatan Pontianak Kota. Metode yang digunakan adalah penyuluhan, diskusi, tanya jawab, praktek sistem pembukuan dan sistem keuangan,. Pengetahuan dan ketrampilan didalam melakukan semua kegiatan merupakan kunci agar semua peserta dapat sukses mengikuti seluruh kegiatan. Kesimpulan yang dapat diambil dari kegiatan ini adalah masyarakat sangat berantusias terhadap materi yang disampaikan karena mereka belum mengetahui hal ini sebelumnya. Pasca kegiatan ini disarankan agar pembinaan kegiatan ini terus dilakukan di bawah naungan RT/RW, dan dibantu untuk memasarkan hasil produk tersebut ke pihak Market atau pameran-pameran, sehingga Kelompok Usaha yang sudah terbentuk tetap berjalan dalam produksi olahan limbah plastik dan kompos dan secara tidak langsung dapat meningkatkan pendapatan keluarga.
\end{abstract}

Kata Kunci : bank sampah, daur ulang, plastik, keuangan, pembukuan

\begin{abstract}
Community Service under taken at "Recycling Money Can" Trash Bank aims to provide technology on how to apply the correct Bank Waste book and finance system and transferred composting technology from organic waste and bag-making technology, beautiful wallets from the remains of plastic wrap or an organic waste to the Group of Independent Young Entrepreneurs and Group Maju Bersama. This devotional activity will be held in Bangkong River Village, Pontianak Kota Sub-district. The methods used are counseling, discussions, frequently asked questions, the practice of book keeping systems and financial systems. Knowledge and skills in doing all the activities is key so that all participants can successfully follow all activities. The conclusion that can be drawn from this activity is that people are very enthusiastic about the material presented because they have not known this before. After this activity it is suggested that the guidance of this activity will continue to be carried out under the auspices of RT / RW, and assisted to market the products to the Market or exhibitions, so that the established Business Groups will continue to run in the production of processed waste and compost can directly increase family income.
\end{abstract}

Keywords: bank waste, recycling, plastics, finance, bookkeeping

1. Fakultas Pertanian, Universitas Tanjungpura, HP 081392205013,E-mail : sure_add@yahoo.com

2. Pertanian, Universitas Tanjungpura, HP 081352284012,E-mail : uraisuci@gmail.com

3. Pertanian, Universitas Tanjungpura, HP 08125721583,E-mail : pin@pplh-untan.or.id 


\section{PENDAHULUAN}

Merubah cara pandang kita dalam memperlakukan sampah adalah prinsip dasar dalam pengelolaan sampah yang ramah lingkungan. Paradigma pengelolaan sampah yang bertumpu pada pendekatan akhir sudah saatnya ditinggalkan dan diganti dengan paradigma baru pengelolaan sampah. Sampah harus dipandang sebagai sumber dana yang mempunyai nilai ekonomis dan dapat dimanfaatkan. Pemanfataan sampah yang bernilai ekonomis misalnya dapat dijadikan kompos dan pakan ternak.

Adapun prinsip utama yang benar dalam mengelola sampah adalah mencegah timbulnya sampah, menggunakan ulang sampah serta mendaur ulang. Jika prinsip ini dijalankan dengan benar dan konsisten, maka akan mendatangkan hasil akhir yang nyata. Pengelolaan sampah yang benar pada akhirnya akan mengurangi polutan, mendatangkan manfaat ekonomi dan menjadikan lingkungan bersih. Jika lingkungan bersih otomatis kesehatan masyarakat juga terjaga. (Anonim, 2009. Sampah di Kota Pontianak)

Bank Sampah merupakan konsep pengumpulan sampah kering dan dipilah serta memiliki manajemen layaknya perbankan, tapi yang ditabung bukan uang melainkan sampah. Warga yang menabung yang juga disebut nasabah memiliki buku tabungan dan dapat meminjam uang yang nantinya dikembalikan dengan sampah seharga uang yang dipinjam.Sampah yang ditabung ditimbang dan dihargai dengan sejumlah uang yang nantinya akan dijual di pabrik yang sudah bekerja sama. Sedangkan plastik kemasan dibeli ibu-ibu PKK setempat untuk didaur ulang menjadi barang-barang kerajinan. (Anonim, 2013. Bank Sampah). Bank Sampah juga dapat dijadikan solusi untuk mencapai pemukiman yang bersih dan nyaman bagi warganya. Dengan pola ini maka warga selain menjadi disiplin dalam mengelola sampah juga mendapatkan tambahan pemasukan dari sampah-sampah yang mereka kumpulkan. (Anonim, 2013. Manfaat dan Sistem Bank Sampah)

Di Pontianak sendiri, keberadaan Bank Sampah baru 1 buah, bernama Wahana Visi Indonesia, yang berdiri 19 Januari 2012, dan mempunyai nasabah sebanyak 125 orang. Metode yang dilakukan adalah nasabah menabung sampah-sampah an organic yang bisa di daur ulang, setelah dikumpulkan dan di beli oleh kelompok usaha atau perusahaan, maka setiap Sabtu mereka dapat mencetak buku tabungannya. Bank Sampah Wahana Visi Indonesia berada di Kelurahan Siantan Tengah, Kecamatan Pontianak Timur dan dijadikan percontohan pembuatan bank sampah bagi kecamatan lainnya. (Anonim, 2009. Sampah di Kota Pontianak).

Mengingat masih kurangnya keberadaan bank Sampah di Kota Pontianak, maka LPM "Wahana Remaja Jaya" yang bergerak dibidang pembuatan kertas daur ulang dan pembuatan pernak-pernik hijab, juga berkeinginan untuk membantu program pemerintah Kota Pontianak mensukseskan "Pontianak Bebas Sampah tahun 2014", dengan mendirikan Bank Sampah "DAUR ULANG DAPAT UANG" yang berlokasi di Gg Pancasila IV No 16. Pontianak

\section{METODE PELAKSANAAN}

Kegiatan pengabdian masyarakat dilakukan dengan khalayak sasaran ibu ibu rumah tangga di Gg Pancasila IV, RT 2, RW X, Bank Sampah Daur Ulang Dapat Uang, kelompok pengrajin barang bekas, dengan cara membagi peserta kedalam 3 kelompok yaitu 1 kelompok pengurus Bank Sampah, dan 2 kelompok usaha barang bekas .

Untuk kepengurusan Bank Sampah di beri Pplatihan pembukuan Bank Sampah yang benar dengan menggunakan sistem 3 buku, yaitu system Buku Besar, system Buku Registrasi dan system Buku Data Nasabah dan pelatihan bagaimana memilah sampah dengan benar, yang memenuhi syarat untuk dijual di Bank Sampah. Untuk kelompok Usaha Barang Bekas diberi Pelatihan pembuatan 
kompos yang benar dan layak jual. Dalam setiap tahapan kegiatan, peserta dirangsang untuk melakukan diskusi agar pelatihan secara teori dapat menjadi dasar untuk melaksanakan praktek tentang cara-cara pembuatan produk. Praktek dilakukan dengan alat dan bahan yang telah disiapkan. Menyajikan hasil analisis usaha pada masing-masing produk yang akan diberikan.

Dalam setiap tahapan kegiatan, peserta dirangsang untuk melakukan diskusi agar pelatihan secara teori dapat menjadi dasar untuk melaksanakan praktek tentang cara-cara pembuatan produk. Praktek dilakukan dengan alat dan bahan yang telah disiapkan. Memperkenalkan produk yang telah jadi dan masyarakat diharapkan turut serta peranannya dalam mengolah dan memasarkan hasil produk.

Pada akhir kegiatan, dilakukan evaluasi terhadap program-program yang telah dilakukan oleh Tim dosen. Evaluasi dilakukan untuk mengetahui hambatan/kesulitan yang dihadapi selama proses kegiatan, dan kemudian didiskusikan untuk diselesaikan.

\section{HASIL DAN PEMBAHASAN}

Dalam kegiatan yang akan dilaksanakan, pada prakteknya akan melibatkan 3 orang mahasiswa untuk membantu Tim dosen di lapangan. Sampah bagi sebagian masyarakat menjadi sumber masalah lingkungan. Selain berbau, sampah juga membuat lingkungan menjadi kotor dan tidak sehat. Sampah seringkali disia-siakan sebagai barang kotor yang tak berguna. Padahal sampah yang tidak bernilai itu bisa menjadi uang dengan cara ditukarkan di Bank Sampah "Daur Ulang Dapat Uang". Bank sampah ini bekerja layaknya seperti bank yang melakukan simpan pinjam, setoran, penarikan dan tabungan. Semua transaksi itu bisa dilakukan asal ada sampahnya.

Di Bank Sampah ini, masyarakat bisa menukar sampah rumah tangga atau sampah lain dengan uang. Gambarannya, masyarakat datang membawa sampah ke bank sampah, kemudian sampah itu dipilahpilah mana yang sampah kaleng, plastik, kertas atau bekas makanan atau tumbuhan. Setelah dipilah sampah akan ditimbang, misalnya sampah kaleng dihargai Rp 1.500 per kilogram, sampah kertas atau plastik Rp 800 per $\mathrm{kg}$.

Keberadaan bank sampah "Daur Ulang Dapat Uang" merupakan salah satu tindakan menciptakan Kerajinan Sampah Yang Bernilai Guna, karena selain bergerak dibidang serupa Bank, Bank Sampah Daur Ulang Dapat Uang juga turut membina beberapa kelompok kerajinan barang bekas, agar terbentuk sinergi putaran ekonomi walaupun dalam skala yang kecil. Sampah kering yang diterima dari para nasabah, sebagian di beli oleh kelompok usaha yang menggunakan sampah kering tersebut, sebagian yang tidak terpakai, dijual kepada pengepul.

Melalui kegiatan IbM yang dilakukan di Bank Sampah "Daur Ulang Dapat Uang" diharapkan terjadi peningkatan modal, peningkatan kinerja kelompok usaha barang bekas, diversifikasi hasil kerajinan sampah an organic dan peningkatan kesejahteraan pengurus dan nasabahnya, dan terakhir Pontianak Kota khususnya Kelurahan Sungai Bangkong, Bebas Sampah.

Pelaksanaan IbM akan melibatkan Bank Sampah "Daur Ulang Dapat Uang” yang dipimpin oleh ibu Sulastri Joko,A.Ma.Pd, sebagai focus kegiatannya dan mengikutsertakan 3 orang pengurus dan 2 Kelompok Usaha Pengrajin Barang Bekas yaitu Kelompok Usaha Remaja Mandiri diketuai oleh Eisar Gabela dan Maju Bersama diketuai oleh ibu Saryait Masing-masing kelompok terdiri dari 6-8 orang dan dalam prakteknya akan diikutsertakan 2 orang mahasiswa. Keterlibatan mahasiswa sangat diperlukan agar pelatihan berjalan efektif, dan kelompok usaha-kelompok usaha barang bekas mengerti sepenuhnya tentang teknologi yang diberikan. 
Setelah terbentuk kelompok, maka selanjutnya masing-masing kelompok akan diberi pelatihan yang meliputi : 1. Pelatihan pembukuan Bank Sampah yang benar kepada pengurus Bank Sampah dengan menggunakan system 3 buku, yaitu system Buku Besar, system Buku Registrasi dan system Buku Data Nasabah, 2. Pelatihan pemilahan sampah dan syarat-syarat sampah yang bisa dibeli oleh Bank Sampah kepada anggota pengurus dan kelompok usaha kerajinan barang bekas, 3. Untuk sampah plastic, kelompok usaha akan diberi pelatihan pembuatan jas hujan, map, tas , 4. Untuk sampah an organic kelompok usaha diberi pelatihan pembuatan kompos yang benar dan layak jual, 5. Budidaya sayur organic dengan system vertikulture menggunakan kompos buatan Bank Sampah
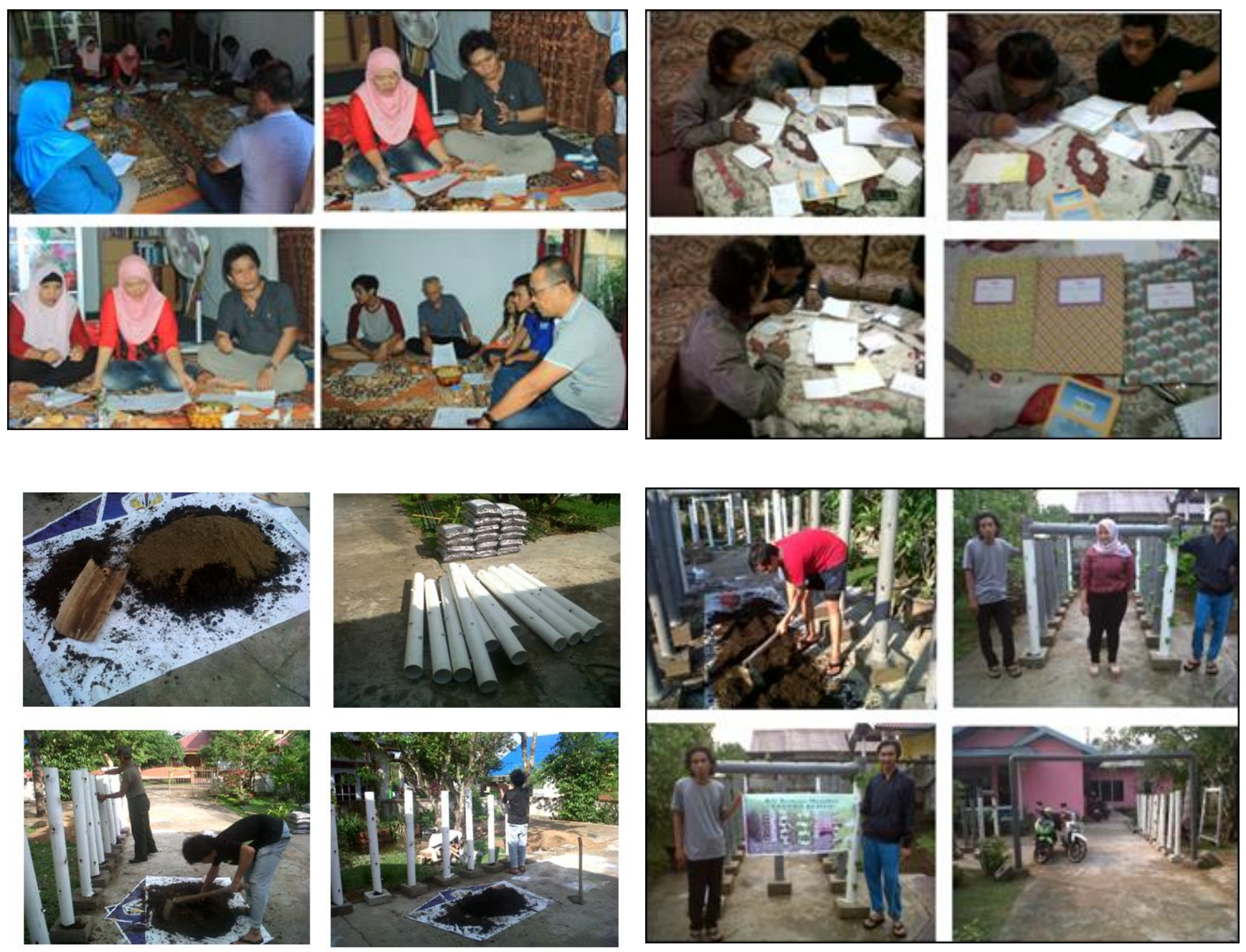

Gambar 3.1 Sosialisasi Bank Sampah dan Pelatihan Pembukuan bagi anggota Bank Sampah 

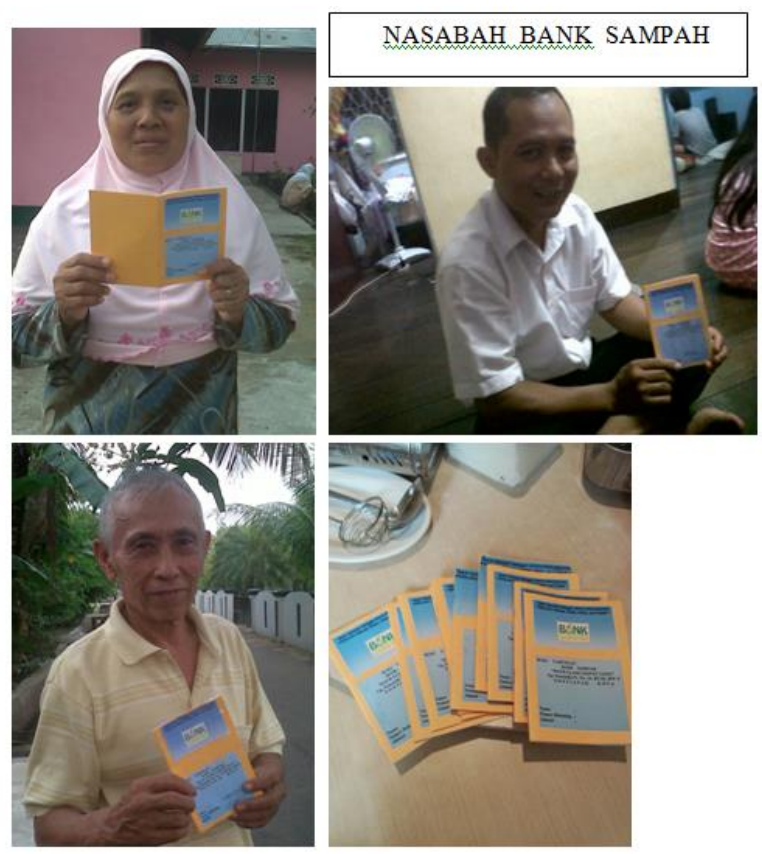

Gambar 3.3 Vertikuture

\section{KESIMPULAN}

Kesimpulan dari kegiatan pengabdian yang telah dilakukan adalah Peranan Bank Sampah Daur Ulang Dapat Uang dapat besar dan berkembang jika didukung eksistensinya oleh masyarakat sekitar RT 2, RW X, Pelatihan pembukuan diperlukan agar administrasi Bank Sampah berjalan dengan baik, Sosialisasi terus perlu dilakukan agar masyarakat selain di Gg Pancasila IV juga mengetahui keberadaan Bank Sampah Daur Ulang Dapat Uang, Keberadaan Bank Sampah Daur Ulang Dapat Uang dapat dijadikan perintis untuk keberadaan Bank Sampah di tempat lain di Kota Pontianak

\section{UCAPAN TERIMAKASIH}

Ucapan terima kasih disampaikan kepada Direktorat Penelitian dan Pengabdian Kepada Masyarakat , Direktorat Jendral Pendidikan Tinggi Kementrian Pendidikan dan Kebudayaan, melalui DIPA Nomor SPDIPA-023 042 415134/2014, Tgl 5 Desember 2013, Sesuai dengan Surat Perjanjian Pelaksanaan Penugasan Program Pengabdian Kepada Masyarakat Nomor : 9617/UN22.13/LK/2014, Tgl 3 Juni 2014

\section{DAFTAR PUSTAKA}

Anonim, 2013. Bank Sampah, Http://yahoo.com.

Anonim, 2013. Manfaat dan Sistem Bank Sampah.htm. Http://yahoo.com.

Anonim, 2009. Sampah di Kota Pontianak. Http://www.yahoo.com 